NBSIR 81-2346

\title{
Energy Management and Control Systems (EMCS) User Satisfaction Study
}

U.S. DEPARTMENT OF COMMERCE

National Bureau of Standards

Center for Building Technology

Building Equipment Division

Washington, DC 20234

August 1981

Department of Energy 1000 Independence Avenue

100

Washington, DC 20585

.456 

NBSIR 81-2346

ENERGY MANAGEMENT AND CONTROL SYSTEMS (EMCS) USER

SATISFACTION STUDY

Gary W. Dickinson

U.S. DEPARTMENT OF COMMERCE

National Bureau of Standards

Center for Building Technology

Building Equipment Division

Washington, DC 20234

August 1981

Department of Energy

1000 Independence Avenue

Washington, DC 20585

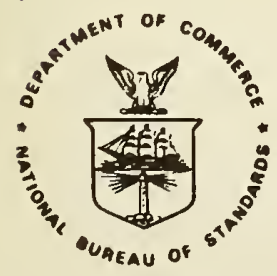

U.S. DEPARTMENT OF COMMERCE, Malcolm Baldrige, Secretary NATIONAL BUREAU OF STANDARDS, Ernest Ambler, Director 



\section{Abstract}

A study of 86 energy management and control systems (EMCS) was made to determine users' satisfaction and perceived system reliability. Many EMC systems reportedly were not meeting users' expectations for energy, dollar, or manpower savings. Nearly one-third of the EMCS users in this study were not satisfied with their system's performance. Undependability of the mamufacturer and proprietary hardware and software were the most common problems reported. Factors found to have no apparent effect on user satisfaction were: (1) the type of facility (with the exception of Hospitals) in which the EMCS is installed, (2) which manufacturer supplied the system, and (3) whether or not the system was owned by the Federal Government.

The data suggest that EMCS maintenance training, in-house maintenance capability, and reduced dependence on the system mamufacturer may help improve user satisfaction. 


\section{Foreword}

This is one of a series of reports documenting National Bureal of Standards (NBS) research and analysis efforts in developing energy and cost data. These data support the Building Energy Conservation Criteria Program sponsored by the Office of Buildings and Community Systems, U.S. Department of Energy (DOE). The work described in this report was supported by DOE/NBS Task Order No. A 008-BCS under Interagency Agreement No. EA 77 A 016010. 


\section{Table of Contents}

Page

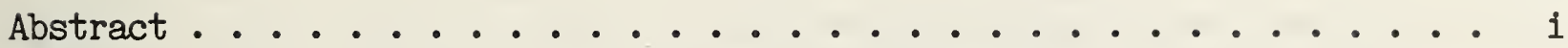

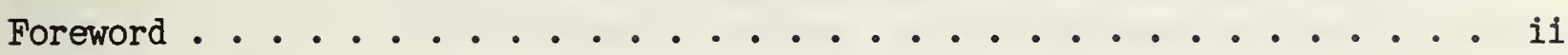

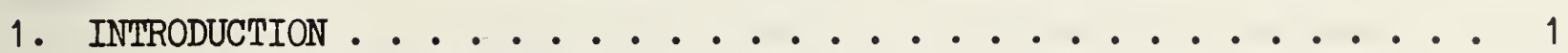

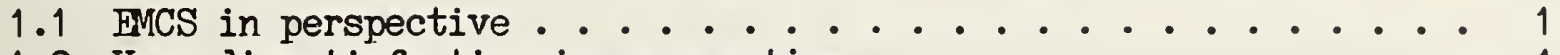

1.2 User dissatisfaction in perspective ........... 1

2. $\mathrm{APPROACH} \ldots \ldots \ldots \ldots . \ldots \ldots$

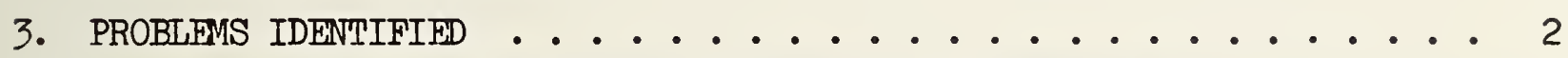

4. CHARACTERISTICS OF SYSTEMS WITH HIGH USER SATISFACTION . . . . . 4

5. SCOPE: HOW EXTENSTVE ARE THE PERCEIVED UNRELIABEITY PROBLENS? . . 6

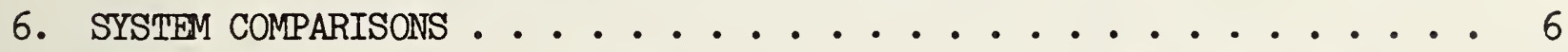

7. SUMMARY $\ldots \ldots \ldots$

8. REFERENCES . . . . . . . . . . . . . . 11

APPENDIX . . . . . . . . . . . . . . 12 


\section{Iist of Figures}

Figure 1 - Problem identification and extent . . . . . . . . . . 3

Figure 2 - Perceived unreliability vs. system characteristics . . . . 5

Figure 3 - Perceived unreliability vs. types of facilities . . . . . 7

Figure 4 - Perceived unreliability vs. system age . . . . . . . . 8 
This report summarizes the findings of a study made to determine failures experienced with energy management and control systems (EMCS). The goals of this study were to determine user's satisfaction with their EMCS, and to identify common problems and possible cures, through interviews with system users.

Because no scientific methor was used in the process of selecting the study participants, there is no way to extrapolate this study data to represent general users of EMC systems.

\subsection{EMCS in perspective}

A common goal of all EMC systems is to reduce the energy costs associated with heating, ventilating, and air-conditioning (HVAC)*, while meeting a pre-selected set of temperature and humidity goals. EMCS included in this study were designed for use in applications ranging from small buildings with as few as 50 monitor and control points, to large multi-building complexes with as many as 15,000 points. These systems have environmental and control sensor data brought together at a central control area where the starting and stopping of HVAC devices can be performed.

The more advanced EMC systems also include one or more computers that turn energy-consuming devices on or off, control dampers, decide which source of heating or cooling is most efficient for present conditions, and shed electrical loads to keep within peak electric demand limits.

\subsection{User dissatisfaction in perspective}

The information presented in this paper is not based on precise failure data; it contains a degree of uncertainty due to user subjectivity. For instance, two users of the same EMC system may perceive its performance differently. Another factor that could affect integrity of the data is the possible reluctance of users to admit failures that some people may construe as inadequate operator skills.

No previous studies about EMCS user satisfaction have been found. However, two guidelines $[1,2]$ that provide detailed approaches to planning, specification, and installation of FMC systems are available. The U. S. Navy guideline [1], referred to as the inter-agency guide spec., is designed to assist all government agencies with their EMCS procurements. The Veterans Administration guideline [2] is a research report focusing on V.A. hospital EMC systems. Although neither guideline's primary effort is the discussion of EMCS problems, they may, by their comprehensive approach, provide a basis for improving performance of these systems.

Among the approaches recommended by these guidelines is the decentralizing of system control. This "distributed processing" technique has the potential for reducing the load on a system's main computer and may help resolve

*A glossary of FMCS terms is located at the end of this report. 
transmission link problems uncovered by this study. The "smart" field interface devices (FID's) recommended are able to contimue functioning when the main computer fails, thus improving reliability.

Since distributed processing systems tend to be more complex and costly than non-distributed EMC systems, only multi-building complexes or very large buildings are likely to benefit from this technology. Some of these new distributed type systems were about to come into use as this study was in progress; but any improvement in EMCS performance as a result of this new technology will have to be determined after these systems have been operating for some time.

\section{APPROACH}

A study was conducted to determine failure experiences in a large mumber of EMC systems installed in diverse facilities. By contacting users close to the system operation, problems causing user dissatisfaction were uncovered.

Discussions with EMCS users centered around the following five questions:

What are or have been the major problem areas?

Are you satisfied with your FMCS performance?

Are you using all of the functions purchased with the system?

Is EMCS maintenance done in-house or by contract?

Has your maintenance team had FMCS maintenance training?

Responses to these questions were pursued in detail. For example, a complaint about hardware was pursued further to localize it to the computer, peripheral devices, or sensor failure. Because of sometimes conflicting responses, careful analysis of the data was necessary. "Yes, I'm satisfied with my system's performance", may have come from the same user who responded, "We are expanding our system with manufacturer B's equipment due to all the problems we had with manufacturer $A^{\prime \prime}$.

Identification of the problem areas and analysis of the study data follow.

3. PROBLEMS IDENTIFIED

Figure 1 shows the problems that were identified during the study and the number of times each problem was reported. Since the complaints are not completely independent, the following examples may help differentiate the categories.

The most common problem reported was undependability of the manufacturer. Most of the complaints concerning this problem centered around the inahility of the mamufacturer to keep a system operational. Inadequate documentation, poorly 


\section{PROBLEMS}

\section{IDENTIFIED}

MFG. IS UNDEPENDABLE

PROPRIETARY PROBLEMS

SOFTWARE PROBLEMS

LIGHTNING, DATA LINK

PERIPHERALS / HDWE.

GETTING SPARE PARTS

$C P U$

SENSORS

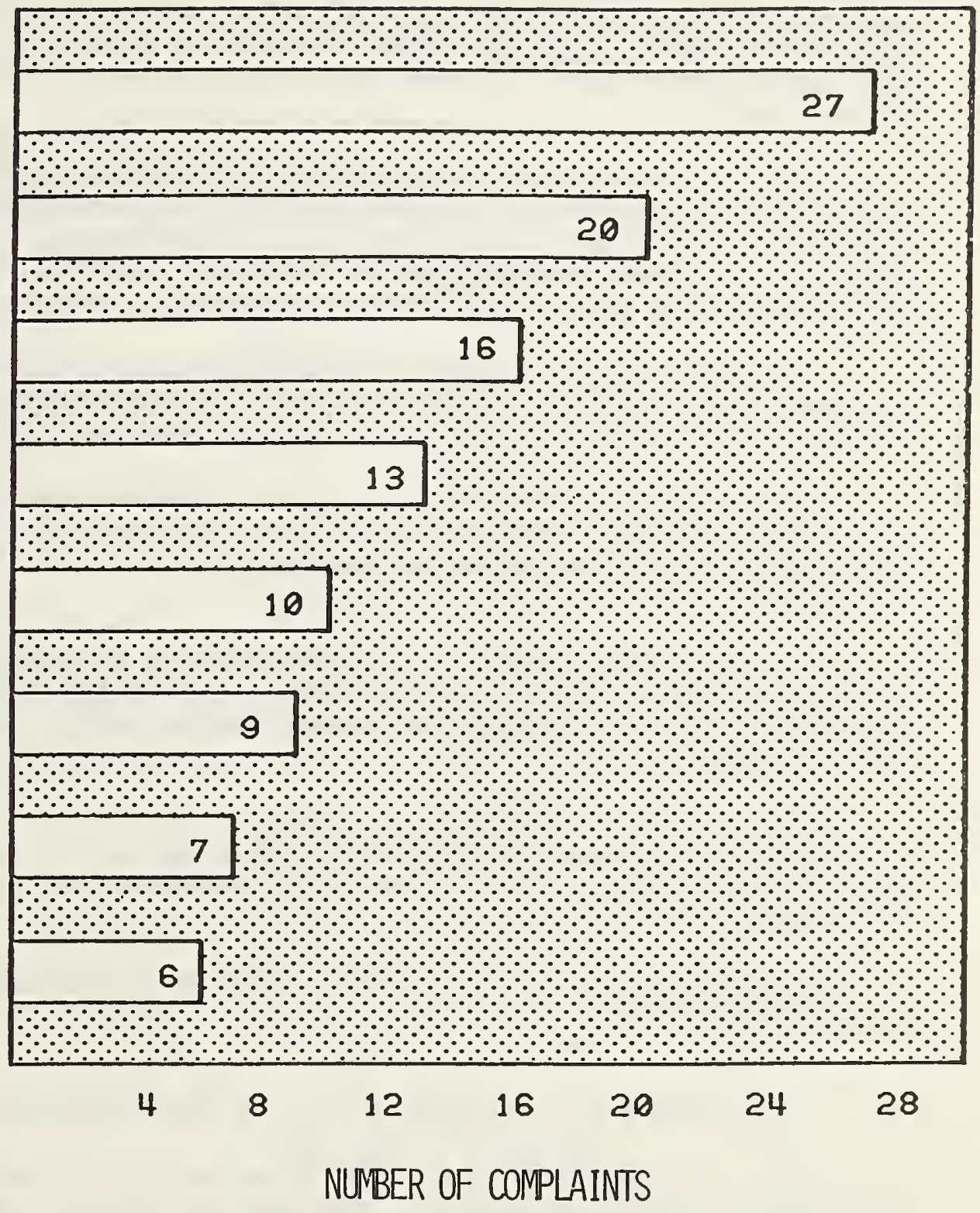

Figure 1 - Problem Identification And Extent 
trained service people, and slow response on service calls were frequent complaints. Other complaints included slow turn-around for software changes and having to make repeated calls to the manufacturer to get repairs made.

Proprietary problems were reported as the most frustrating. Skilled technicians at EMCS sites were unable to repair hardware or to make software changes because the manufacturer refused to supply adequate documentation. In some cases, users could not obtain hardware or software maintenance training from the system supplier because such training would reveal proprietary information.

Users mentioned only a few specific software problems. Among them was the inability of the software to perform simple data gathering or averaging routines. Other software problems were fairly general, such as intermittent failures in system programs causing excessive downtime, or the inability to bring optimizing programs up to an acceptable performance level.

In several cases, lightning destroyed major electronic assemblies in FMC systems. Most other related complaints were about noise effects on the data transmission link which resulted in significant data losses.

Peripheral device and other hardware problems were broadly distributed. There were slightly more complaints about printers, but tape and disc drives, loop remotes, and data gathering panels all had about the same number of reports of failures.

Obtaining spare parts was also reported as a frustrating problem. Some users encountered delays of several weeks in getting parts, while others encountered delays exceeding six months before getting replacement parts for their systems.

Most central processing unit (CPU) problems were intermittent and, like intermittent software problems, the source was hard to locate and that caused much system downtime. Only a few users reported specific CPU problems such as temperature sensitivity.

Complaints about sensor problems were very consistent: all were about calibration drift.

\section{CHARACTERISTICS OF SYSTEMS WIMH HIGH USER SATISFACTION}

Data indicated that there were three major differences between systems with high and low user satisfaction. The data in Figure 2 show user satisfaction may be related to the three characteristics. Many more users who have had EMCS maintenance training perceived their systems as reliable than unreliable. Also, more than twice as many users who have in-house maintenance capability judged their system's performance to be reliable than unreliable.

These two maintenance-related characteristics may be associated with the third, which is the use of optimizing functions. These data show that for the 
SYSTEM CHARACTERISTICS

HAVE EMCS

MAINT. TRAINING

HAVE IN-HOUSE

MAINTENANCE

USE OPTIMIZING

FUNCTIONS
$R=$ PERCEIVED RELIABLE SYSTENS

$U$ = PERCEIVED UNRELIABLE SYSTENS

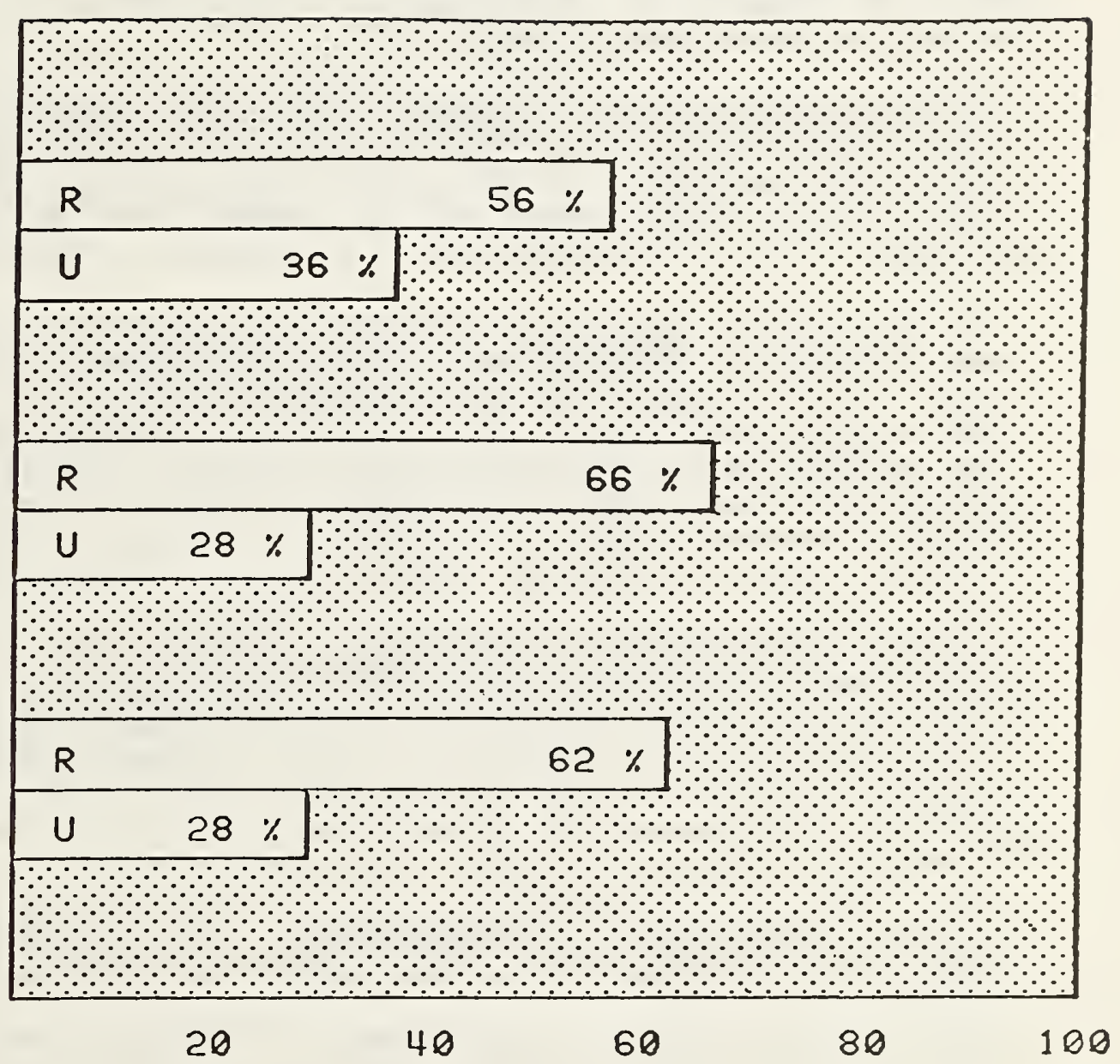

PERCENT OF SYSTEMS

Figure 2 - Perceived Unreliability VS. System Characteristics 
systems that have optimizing capability, more than twice as many users reported that their systems are reliable than unreliable.

\section{SCOPE: HOW EXTENSIVE ARE THE PERCEIVED UNREIIABILITY PROBLEMS?}

Of the 86 EMC systems included in this study, 29\% of the users were not satisfied with their system's performance. While making a comparison of the data, several areas were investigated. These were: (1) the type of facility the system is installed in, (2) system age, (3) manufacturer, and (4) user group. Analysis of these data follows.

Perceived Unreliability vs. Types of Facilities - Figure 3 - The data presented on this graph show that all other facilities have EMCS unreliability problems greater than hospitals. If the hospital data were not included with the other study data, the results would show an increase from 29\% to more than 35\% of users who were not satisfied with their system's performance.

Why do the hospitals have systems which appear more reliable than those in other facilities? Studying age profile, mamfacturer, and system characteristics does not account for this performance difference. One factor that contributed to hospital reliability is the V.A. "Guidelines" [2]. Increasing user awareness of latent problems and providing an effective approach for handling EMCS technology in the hospitals resulted in improved reliability. Since V.A. hospitals make up two-thirds of the total hospital sample, the effect of their improved reliability affects results for the entire group.

Perceived Unreliability vs. System Age - Figure 4 - The overall trend of this graph shows a general increase in perceived unreliability with increasing age. This seems reasonable since failures in mechanical parts are often due to wear and fatigue, which can increase with age. No reason has been found to explain the break in trend shown by the highly unreliable 4-year-old systems (1976 vintage). Also, because the data for systems that are less than two years old is based on a very small sample, thase results could be misleading.

Perceived Unreliability vs. Manufacturers - The study data indicated that all manufacturers' systems have a similar perceived reliability record.

Perceived Unreliability vs. User Groups - To compare perceived reliability information, the system data were separated by user group into federal military (25 systems), federal non-military (4I systems), and non-federal (20 systems). Comparison of these data shows that each user group had similar perceived reliability experiences.

\section{SYSTEM COMPARISONS}

During the study two differently structured EMCS installations were observed to compare user experiences and system configurations. Both systems are described below and are considered to be reliable by the system operators. 
TYPES OF

\section{FACILITIES}

HOSPITALS

POSTAL SERVICE BULK MAIL CENTERS

AIR FORCE BASES

OTHER

(UNIVERS I TIES, OFF ICES, STORES)

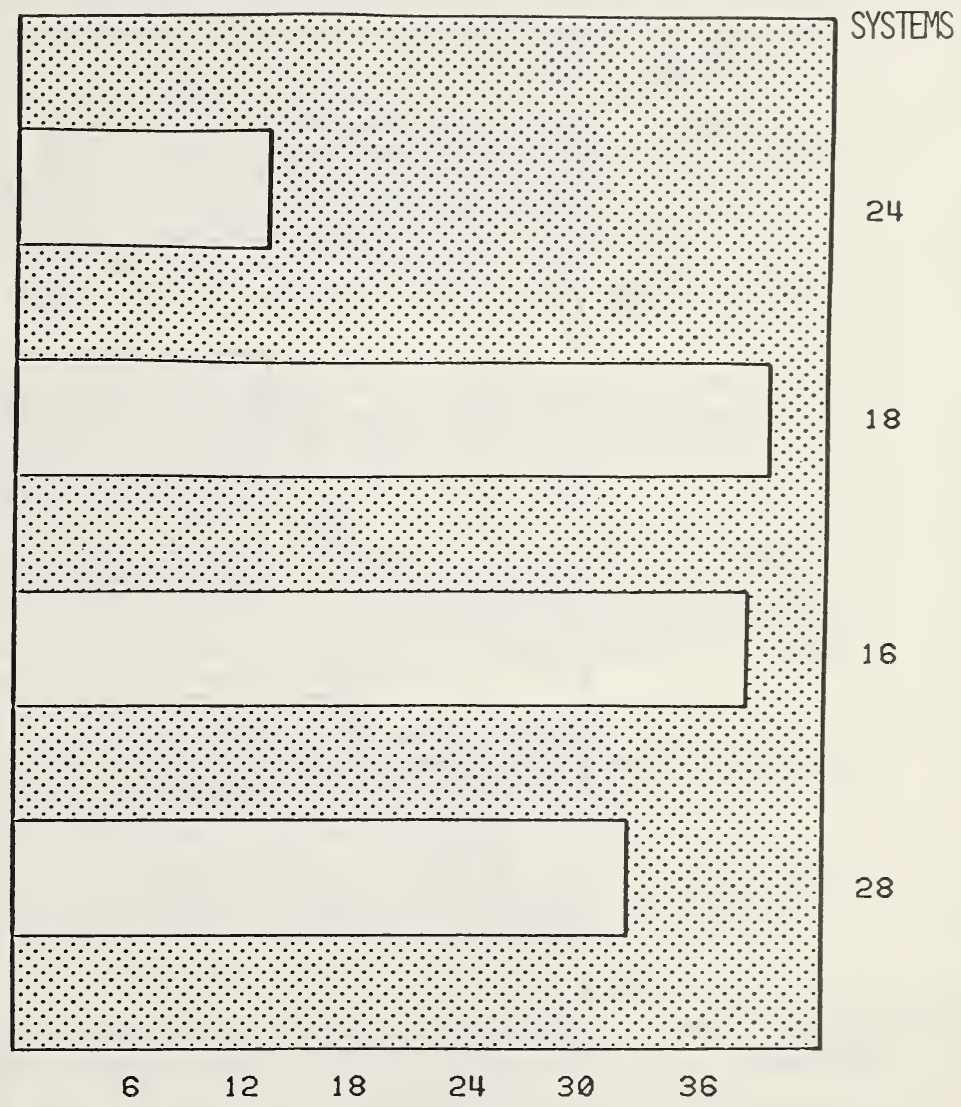

PERCENT OF SYSTENS THAT ARE PERCEIVED TO BE UNRELIABLE

Figure 3 - Perceived Unreliability VS. Types of Facilities 


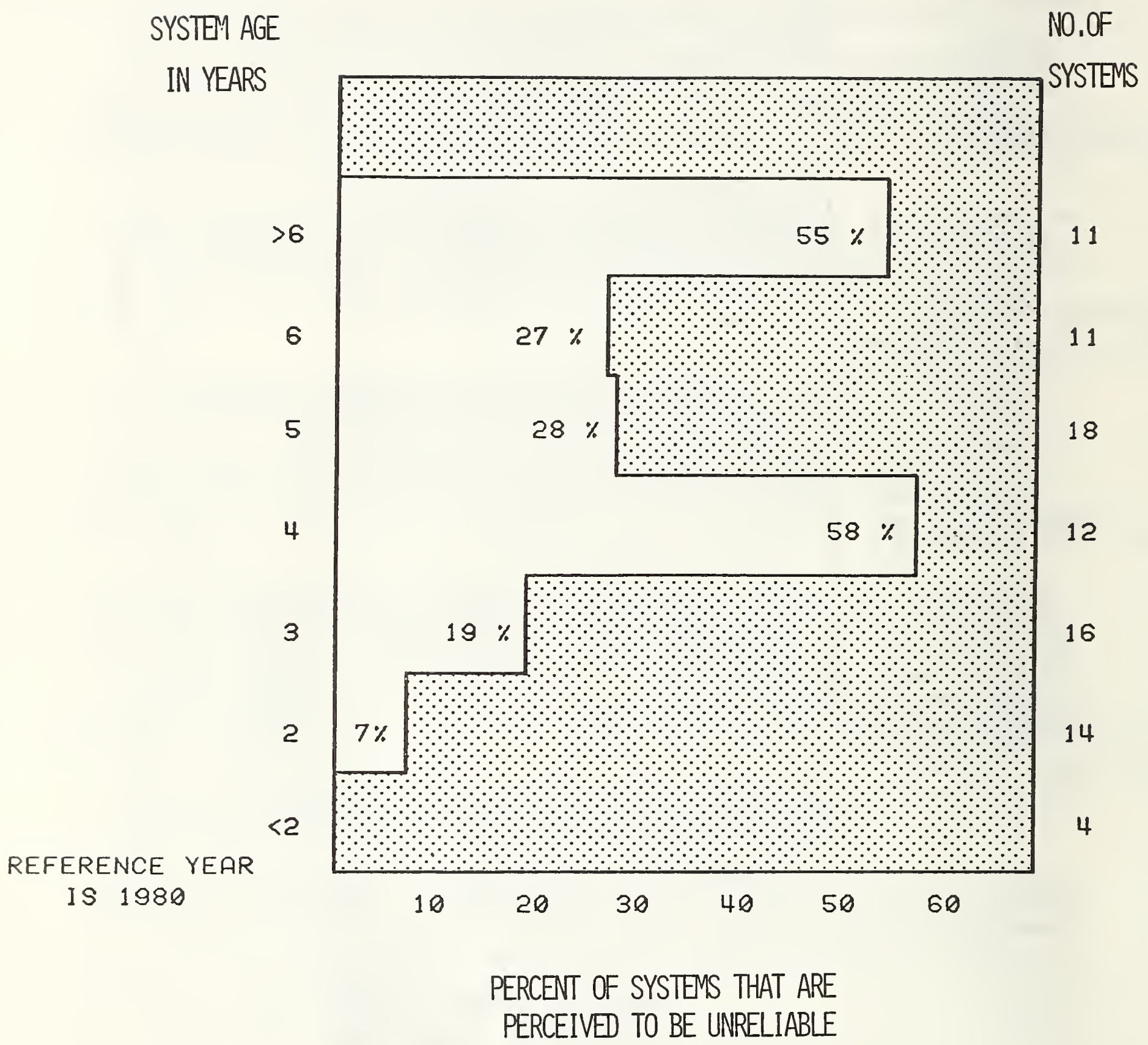

Figure 4 - Perceived Unreliability VS. System Age 
The first system is a relatively small system configured like many in the study that do not have optimizing functions. It has remote monitoring and data logging of control points, and is used as a manual start/stop center for singlebuilding HVAC equipment. The automatic mode is not used because the operators anticipate heating or cooling load changes and adjust the system manually. They are performing functions like optimum start/stop and load shedding.

One factor contributing to this system's perceived reliability is in-house maintenance. Many replacement parts are kept on hand to assist in repairing by replacing suspect components. The system manufacturer is only occasionally called for repair assistance, while the system operators play the major role in making this system reliable and effective. It should be noted, however, that this system does not operate near its potential for automatic control with the existing equipment.

The second system is one of the largest in the country, and is used as a multiple-building HVAC control system. It has many optimizing functions including optimum start/stop, load shedding, chiller/boiler optimization, and enthalpy control. Also, a complete back-up computer and trend log are available to ensure reliable operation.

Some of the factors that users say contribute to this system's reliability are: (1) personnel training, (2) English language man-machine interfaces at control consoles, (3) electric surge protection to minimize lightning problems, (4) as-built drawings and documentation, and (5) maintenance management software to keep track of preventive maintenance schedules.

Five full-time people are responsible for system operation during each three-shift work day, and are assisted by the system manufacturer in maintenance tasks. Personnel commitment, capability of using optimizing functions, and back-up systems are all factors in this system's high reliability.

This comparison of two dissimilar systems shows that user satisfaction or perceived reliability does not depend on system size or the use of automatic controls.

\section{SUMMARY}

The data show that many problems do exist with FMC systems; about one-third of the system users in this study reported trouble keeping their system operational. Although the study revealed no causative factors for the problems, some associative factors have been identified. Since data suggest that about half of all identified problems are related to excessive dependence on the system mamufacturer, reducing that dependence could be a key factor in improving EMCS reliability.

Analysis of system characteristics revealed that EMCS maintenance training and in-house maintenance capabilities were found much more often with those systems that users perceived to be reliable. Also, there were more than twice as many reports of reliable systems than unreliable systems in the group of users whose systems have optimizing capability. 
System age was found to affect reported reliability in a logical wav; that is, perceived unreliability increases with increasing age. To minimize old age effects on EMCS performance some users recommend that a preventive maintenance program be implemented.

From other system data, three factors were found to have no apparent effect on perceived reliability: (I) the type of facility (with the exception of Hospitals) in which the system is installed, (2) which mamufacturer supplied the system, and (3) whether or not the system was owned by the Federal Government. 
8. References

(I) Guide Specification for Energy Monitoring and Control Systems (U.S. Navy Ref. \# TS-13941 thru 50) March 1980.

(2) Guidelines for Energy Management and Control Systems for V.A. Facilities (Veterans Administration Project \#99R082) June 1979. 


\section{Appendix I}

Glossary of EMCS Terms

Control points - switches through which remote control functions are accomplished.

Distributed processing - a technique that uses microcomputer controllers at remote sites to collect, process, and store sensor data until called for by the central computer.

Electric demand limit - a predetermined rate of electricity use beyond which large additional fees are added to a customer's electric bill.

Enthalpy control - an optimizing function that allows use of outside air for cooling when total heat content of the outside air is less than that of the inside air.

HVAC - heating, ventilating, and air-conditioning.

Intermittent hardware/software problems - those problems that occur randomly and cannot be initiated by any known sequence of events.

Load shedding - an optimizing function that cycles electrical loads off and on to keep energy use below the electric demand limit.

Optimizing functions - those which improve efficiency of the EMCS by automatic, real-time adjustment of system equipment.

Optimum start/stop - an optimizing function that saves energy by starting or stopping systems after evaluating weather conditions, thermal inertia of the buildings, and hours of occupancy.

Trend $\log$ - a display of system parameters that is updated frequently to establish temperature and energy use trends.

Unreliability - a broad term which in this study indicates user dissatisfaction with EMCS performance. 
BIBLIOGRAPHIC DATA

SHEET (See in structions)

$$
\begin{aligned}
& \text { 1. PUBLICATION OR } \\
& \text { REPORT NO. } \\
& \text { NBSIR 81-2346 }
\end{aligned}
$$

2. Performing Organ. Report Nod 3. Publication Date

August 1981

4. TITLE AND SUBTITLE

Energy Management and Control Systems (EMCS)

User Satisfaction Study

5. AUTHOR(S)

Gary W. Dickinson

6. PERFORMING ORGANIZATION (If joint or other than NBS, see instructions)

7. Contract/Grant No.

NATIONAL BUREAU OF STANDARDS

DEPARTMENT OF COMMERCE

WASHINGTON, D.C. 20234

8. Type of Report \& Period Covered

9. SPONSORING ORGANIZATION NAME AND COMPLETE ADDRESS (Street, City, State, ZIP)

Department of Energy

1000 Independence Ave.

Washington, D.C. 20585

10. SUPPLEMENTARY NOTES

Document describes a computer program; SF-185, FIPS Software Summary, is attached.

11. ABSTRACT (A 200-word or less factual summary of most significant information. If document includes a significant bibliography or literature survey. mention it here)

A study of 86 energy management and control systems (EMCS) was made to determine users' satisfaction and perceived system reliability. Many EMC systems reportedly were not meeting users' expectations for energy, dollar, or manpower savings. Nearly one-third of the EMCS users in this study were not satisfied with their system's performance. Undependability of the manufacturer and proprietary hardware and software were the most common problems reported. Factors found to have no apparent effect on user satisfaction were: (1) the type of facility (with the exception of Hospitals) in which the EMCS is installed, (2) which manufacturer supplied the system, and (3) whether or not the system was owned by the Federal Government.

The data suggest that EMCS maintenance training, in-house maintenance capability, and reduced dependence on the system manufacturer may help improve user satisfaction.

12. KEY WORDS (Six to twelve entries; alphabetical order; copitalize only proper names; and seporate key words by semicolons) building energy conservation systems; EMCS; energy management; energy monitoring and control systems; HVAC controls; relibility study

13. AVAILABILITY

X Unlimited

For Official Distribution. Do Not Release to NTIS

$\square$ Order From Superintendent of Documents, U.S. Government Printing Office, Washington, D.C. 20402.

14. NO. OF PRINTED PAGES

\section{7}

15. Price

$\$ 5.00$

X] Order From National Technical Information Service (NTIS), Springfield, VA, 2216I 

